\title{
Relationship of Oxidative Stress with HIV Disease Progression in HIV/HCV Co-infected and HIV Mono-infected Adults in Miami
}

\author{
Dong-Ho Shin, Sabrina S. Martinez, Mary Parsons, Dushyantha T. Jayaweera, Adriana Campa, and \\ Marianna K. Baum
}

\begin{abstract}
Background: HIV and HCV infections are both characterized by increased oxidative stress. Information on the magnitude of this increase and its consequences in HIV/HCV co-infection and viral replication is limited. We investigated the relationship between oxidative stress and HIV-progression in HIV/HCV co-infected and HIV mono-infected adults.
\end{abstract}

Methods: 106 HIV/HCV co-infected and 115 HIV mono-infected participants provided demographic information and blood to determine 8-oxo-dG and percent oxidized glutathione.

Results: HIV/HCV co-infected subjects had higher percent oxidized glutathione, higher HIV viral load, lower mtDNA copies and higher liver fibrosis than mono-infected subjects. In a small sample of HIV/HCV co-infected participants with liver biopsy, 8-oxo-dG was significantly lower in participants with low fibrosis scores than those with high fibrosis scores, and the grade of inflammation was strongly associated with oxidized glutathione.

Conclusions: HIV/HCV co-infection seems to diminish the capacity of the antioxidant system to control oxidative stress, and increases HIV replication.

Index Terms - Glutathione (GSH), HIV/HCV co-infection, liver fibrosis index (FIB-4), oxidative stress.

\section{INTRODUCTION}

Human immunodeficiency virus (HIV) is a lentivirus (a member of the retrovirus family) that causes acquired immunodeficiency syndrome (AIDS) [1]-[2], a disease in humans in which progressive failure of the systemic immune function allows life-threatening opportunistic infections and cancers to thrive. HIV interferes with the human body's ability to fight the organisms that cause disease by damaging human immune system. Hepatitis $\mathrm{C}$ is an infectious disease affecting primarily the liver, caused by the hepatitis $\mathrm{C}$ virus (HCV) [3]. Chronic infection of HCV causes a state of chronic oxidative stress and can lead to scarring of the liver and ultimately contribute to liver fibrosis, cirrhosis, and carcinogenesis [4]-[6]. An important similarity between chronic hepatitis C and HIV/AIDS is that both infections appear to progress more rapidly in situations of increased oxidative stress [7].

Manuscript received April 25, 2012; revised May 30, 2012. This work was supported by the National Institute on Drug Abuse (Grant No. R01DA023405).

Dong-Ho Shin, Sabrina S. Martinez, Mary Parsons, Adriana Campa, and Marianna K. Baum are with Florida International University, Miami FL 33199 USA (e-mail: shindong@fiu.edu, baumm@fiu.edu).

Dushyantha T. Jayaweera is with Jackson Memorial Hospital, University of Miami, Miami FL 33136-1096 USA.
Oxidative stress refers to a state in which there is an overabundance of molecules called free radicals. Free radicals can damage cells and are involved in the processes of inflammation and scarring [7].

Glutathione (GSH) is a small, ubiquitous antioxidant that plays key regulatory roles in metabolic and cell-cycle-related functions [8]-[12]. This cysteine-containing tripeptide (gamma glutamylcysteinylglycine) provides the principal intracellular defense against oxidative stress caused by reactive oxygen species such as free radicals and peroxides [13] and participates in detoxification of many physiological molecules [14]. GSH depletion, caused for example by acetaminophen overdose and excessive alcohol consumption, results in hepatic and renal failure and ultimately in death [14]. Deficiency of glutathione can lead to immune suppression, decline of immune system function, and an increase in HIV replication [15]. The level of glutathione has shown to be significantly depressed in many people with hepatitis $C$ [16]. HIV-infected people tend to have subnormal GSH levels in plasma [17]-[18], lung epithelial lining fluid [19], peripheral blood mononuclear cells (PBMC) [20] and, as determined by measuring GSH as intracellular glutathione-S-bimane fluorescence (GSB) with the fluorescence-activated cell sorter (FACS), in individual CD4 T and other blood cells [20]-[22]. In vitro studies show that lowering intracellular GSH levels decreases cell survival [23], alters T cell functions [24], and increases HIV replication [25]-[26], NF-kB activation [25]-[26], and sensitivity to tumor necrosis factor-induced cell death [27]. Clinical studies reported that GSH status is associated with impaired survival in HIV/AIDS disease [28]-[29] and may play a role in disease pathology [30]. As the liver is the most important organ of plasmatic GSH production, low levels of glutathione have been reported to have association with more active liver disease on liver biopsy, increased levels of the liver enzyme ALT, and resistance to antiretroviral drugs and interferon treatment [31]. Low glutathione has been suggested as a factor in resistance to treatment that is seen with both interferon treatment for HCV and anti-viral therapy for HIV [31]. Moreover, Highly Active Antiretroviral Therapy (HAART) appears to increase chemically reactive species in circulation, possibly by producing more oxidized metabolites deriving from the interaction between ROS and infected cell biomolecules [32]-[37]. This is supported by several biochemical mechanisms, such as mitochondrial interference, following treatment with HAART-NRTI (Nucleoside Reverse Transcriptase Inhibitors) [35]-[37], and activation of the 
P450 hepatic system by HAART, when including Protease Inhibitors (PI) [34].

Although HIV and HCV infections are both characterized by increased oxidative stress, information on the magnitude of the increase in oxidative stress and its consequences in $\mathrm{HIV} / \mathrm{HCV}$ co-infection and viral replication is limited. The findings of this study indicate that $\mathrm{HIV} / \mathrm{HCV}$ co-infection may contribute to higher oxidative stress and further disease progression than HIV mono-infection. The objective of this study was to assess the oxidative stress and HIV disease progression in $\mathrm{HIV} / \mathrm{HCV}$ co-infection compared to HIV mono-infection in an adult population in Miami, Florida.

\section{MATERIALS AND Methods}

\section{A. Materials}

The DNA extraction kit, QIAamp DNA blood mini kit, was purchased from Qiagen (Valencia, CA). The protein assay kit, BCA protein assay kit, was purchased from Pierce Biotechnology (Rockford, IL). All gene specific DNA primers were purchased from Sigma-Aldrich (St. Louis, MO). iQ SYBR Green Supermix was purchased from BioRad (Hercules, CA). Human 8-oxoguanine DNA glycosylase (hOGG1) was purchased from New England BioLabs (Ipswich, MA). Malondialdehyde (MDA) assay kit was purchased from Northwest Life Science Specialties, LLC (Vancouver, WA, Canada). Complex I and IV human enzyme activity kits were purchased from Mitosciences (Eugene, OR) Glutathione (GSH) colorimetric detection kit was purchased from Arbor assays (Ann Arbor, MI). BD Vacutainer CPT tubes and Royal blue tubes were purchased from BD Diagnostics (Franklin Lakes, NJ). 5-sulfosalicyclic acid and 2-vinylpyridine (97\%) were purchased from Acros Organics (Morris Plains, $\mathrm{NJ}$ ).

\section{B. Population}

The study population of $106 \mathrm{HIV} / \mathrm{HCV}$ co-infected and 115 HIV mono-infected participants was recruited for this study in Miami from April 2009 to December 2011. Participants were between ages 18 and 60, and confirmed with HIV seropositive status. This study was approved by the Florida International University (FIU) Institutional Review Board. Written informed consent was obtained from all participants and clinical research was conducted according to guidelines for human experimentation as specified by the US Department of Health and Human Services and authors'

\section{Preparation of Plasma and PBMCs}

A $24 \mathrm{ml}$ sample of blood from each participant was obtained in a fasting state defined as nothing by mouth except water for $\geq 12$ hours prior to the blood draw. Blood draws were performed using BD Vacutainer CPT and Royal Blue tubes in the FIU Health Study clinic at the Borinquen Health Care Center in Miami, Florida. Collected blood samples were transported in a cold transporter to the FIU laboratory within 2 hours of collection and immediately subjected to sample preparation. Plasma and PBMCs were recovered according to the instructions of BD Vacutainer Blood Collection System with modification by author. The collected plasma and
PBMCs were divided into appropriate volumes and quantities of cells in accordance with the designated application and stored at $-80^{\circ} \mathrm{C}$ until use.

\section{Preparation of DNA and Total Protein}

Total DNA of each participant was extracted from PBMCs ( $2 \times 10^{6}$ cells) using QIAamp DNA blood mini kit (Qiagen) according to the manufacturer's instructions. The extracted DNA was subjected to determination of concentration by a spectrophotometric method and securely stored at $-20^{\circ} \mathrm{C}$ until use. Total protein was extracted from PBMCs of 3.0 5.5 x $10^{6}$ cells according to the method described elsewhere [38]. The purified protein was undergone for estimation of concentration using BCA protein assay kit (Pierce Technology) and stored at $-20^{\circ} \mathrm{C}$ for future application after appropriate concentration determined.

\section{E. Enzyme Digestion and Quantitative PCR of mtDNA Damage}

Four hundred nanograms of total genomic DNA were digested to completion with 2 units of hOGG 1 at $37^{\circ} \mathrm{C}$ for 1.5 hours. The hOGG1was treated to remove mutagenic lesions and form a strand break in the ribose-phosphate backbone of the DNA strand as described elsewhere [39]. The hOGG1enzyme is an 8-oxoguanine DNA glycosylase which acts both as a N-glycosylase and an apurinic (AP) lyase [40]-[41]. The reaction products containing an $80 \mathrm{ng}$ mass of digested DNA were immediately applied to the quantitative PCR. Real-time quantitative PCR of 8-oxo-2' deoxyguanosine (8-oxo-dG) on mtDNA was performed using iQ5 real-time PCR system (BioRad, Hercules, CA). Four gene-specific primers with incorporation of redesigning of a reverse primer were used for the real-time quantitative PCR [39], [42]. The sequences of the gene-specific primer set employed for the real-time PCR amplification of mitochondrially encoded NADH dehydrogenase 1 gene in human (MT-ND1) were as follows: forward primer, 5'CACCCAAGAACAGGGTTTGT-3'(nucleotide numbers, $3212 \sim$ 3231) and reverse primer, 5'-TGGCCATGGGTATGTTGTTAA-3'(nucleotide numbers, 3319 3299) registered in GenBank (accession number: NC_012920). The primer sequences used for real-time PCR amplification of positive control, $18 \mathrm{~S}$ ribosomal RNA (rRNA) gene, were as follows: forward primer, 5'-TAGAGGGACAAGTGGCGTTC-3'(nucleotide numbers, $1586 \sim 1605)$ and reverse primer, 5'-CGCTGAGCCAGTCAGTGT-3'(nucleotide numbers, 1689 1672) registered in GenBank accession number: K03432). The quantitative PCR was performed under the following conditions in duplicate: 1 cycle of hot start at $95^{\circ} \mathrm{C}$ for $10 \mathrm{~min}, 43$ cycles of annealing/extension at $95^{\circ} \mathrm{C}$ for $15 \mathrm{~s}$ and $60^{\circ} \mathrm{C}$ for $1 \mathrm{~min}$. The result of the amplified target DNA fragments was measured by the intensity of fluorescence SYBR green at the end of every extension phase at $60^{\circ} \mathrm{C}$.

\section{F. Measurement of Level of Glutathione}

Whole blood samples for the determination of all forms of GSH were collected in BD blood collection tubes containing $\mathrm{K}_{2}$ EDTA as an anticoagulant. Appropriate amount of whole blood freshly collected was mixed immediately with $5 \%$ sulfosalicyclic acid at a ratio of 1:1 and was subjected to the 
further procedures of the sample preparation according to the manufacturer's instructions [43]. The recovered GSH samples were stored at $-80^{\circ} \mathrm{C}$ until use. The levels of glutathione (total, reduced and oxidized forms) in whole blood were measured using glutathione colorimetric detection kits (Arbor Assays, Ann Arbor, MI) according to the manufacturer's instructions after treatment with 2-vinylpyridine [44]. The level of glutathione in each sample was diluted appropriately according to the sample's condition and was subjected to the measurements of concentrations ranging $0.78-25 \mathrm{uM}$ at an OD450 $\mathrm{nm}$ with a GSH standard run with each set of samples.

TABLE I: COMPARISON OF DEMOGRAPHICS, CD4 AND VIRAL LOAD BETWEEN HIV/HCV CO-INFECTION AND HIV MONO-INFECTION.

\begin{tabular}{|c|c|c|c|c|}
\hline Characteristic & $\begin{array}{l}\text { Overall } \\
(n=221)\end{array}$ & $\begin{array}{c}\text { HIV/HCV } \\
(n=115)\end{array}$ & $\begin{array}{l}\text { HIV only } \\
(n=106)\end{array}$ & P-value \\
\hline Male $[\%(n)]$ & $66.21 \%(145)$ & $67.62 \%(77)$ & $64.91 \%(68)$ & 0.674 \\
\hline Age (years) $[$ mean $\pm \mathrm{SD}]$ & $49.26 \pm 6.43$ & $50.76 \pm 6.90$ & $47.90 \pm 5.67$ & $0.001^{*}$ \\
\hline $\mathrm{BMI}[$ mean $\pm \mathrm{SD}]$ & $27.61 \pm 5.27$ & $27.68 \pm 5.74$ & $27.58 \pm 5.02$ & 0.905 \\
\hline Waist/hip ratio $[$ mean $\pm \mathrm{SD}]$ & $0.93 \pm 0.08$ & $0.918 \pm 0.08$ & $0.933 \pm 0.08$ & 0.225 \\
\hline CD4 cell count $($ cells/uL) $[$ mean $\pm \mathrm{SD}]$ & $526.77 \pm 353.90$ & $539.70 \pm 335.90$ & $515.30 \pm 370.20$ & 0.615 \\
\hline HIV viral load $\left(\log _{10}\right.$ copies $\left./ m L\right)[$ mean $\pm \mathrm{SD}]$ & $2.52 \pm 1.17$ & $2.73 \pm 1.28$ & $2.33 \pm 1.03$ & $0.012 *$ \\
\hline Receiving ART $[\%(n)]$ & $81 \%(179)$ & $99.1 \%(114)$ & $57.6 \%(61)$ & 0.303 \\
\hline
\end{tabular}

* Indicates statistically significant results.

\section{G. Liver Fibrosis}

In order to determine the stage of liver disease and the extent of liver fibrosis, the fibrosis index (FIB-4) was measured [45]. The FIB-4 is a validated and non-invasive method to estimate fibrosis stage. This method uses a formula based on age, aspartate aminotransferase (AST), alanine aminotransferase (ALT) and platelet count that corresponds with the stage of liver fibrosis in HIV/HCV co-infection [46]. We determined whether there was a meaningful difference in the proportion and degree of liver damage between the $\mathrm{HIV} / \mathrm{HCV}$ co-infected and the HIV mono-infected groups and whether there was a relationship between the stage of liver disease and the levels of oxidative stress.

\section{H. Statistical Analysis}

Data analysis was performed using a 2-tailed Student's t test with pooled variance, as well as regression analyses. Data are expressed as mean \pm S.D. of at least two sample replicates, unless stated otherwise. Student's t test was used to compare the mean values between the HIV mono-infected and HIV/HCV co-infected groups.

\section{RESULTS AND DISCUSSION}

\section{A. Population}

Analysis was performed on a total of 221 participants, of which 115 (52\%) were HIV/HCV co-infected and 106 (48\%) were HIV mono-infected (Table I). The sample was $66 \%$ male and $34 \%$ female. Of these subjects, the ethnic breakdown was $68.42 \%$ Black Non-Hispanic, $20.57 \%$ White Hispanic, 6.70\% White Non-Hispanic, 3.35\% Black Hispanic, and $0.96 \%$ American Indian. Among all subjects, the mean age was $49.26 \pm 6.43$ years. Mean values for BMI and
Waist/Hip Ratio were 27.61 and 0.93 , respectively. The percentage of subjects receiving ART was $81 \%$. The only significant differences in demographic characteristics between the HIV/HCV co-infected and HIV mono-infected groups were in age; the co-infected group was significantly older $(50.76 \pm 6.90$ vs. $47.90 \pm 5.67, \mathrm{p}=0.001)$. To account for this difference, all subsequent analyses were controlled for age.

\section{B. CD4 Cell Count and HIV Viral Load}

Among all study participants, mean CD4 cell count was $526.8 \pm 353.9$ cells/uL and mean HIV viral load was $2.52 \pm$ $1.17 \log _{10}$ copies/mL. CD4 cell count did not differ significantly between the HIV/HCV co-infected and HIV mono-infected groups, but a significant difference was observed in HIV viral load. Subjects co-infected with $\mathrm{HIV} / \mathrm{HCV}$ had a mean viral load of $2.73 \pm 1.28 \log _{10}$ copies/mL, while HIV mono-infected subjects had $2.33 \pm$ $1.03 \log _{10}$ copies $/ \mathrm{mL}(\mathrm{p}=0.012$ ) (Table I) after controlling the analyses for age, gender, and antiretroviral medication adherence. This higher HIV viral load observed in co-infected individuals suggests an effect of HIV/HCV co-infection on increasing rates of HIV viral replication by diminishing the ability of the immune system to control viral load. This result supports literature suggesting accelerated HIV disease progression in states of elevated oxidative stress, such as that found in HCV co-infection [7], [4]-[6]. The lack of relation between CD4 cell count and HCV status indicates that HIV/HCV co-infection does not directly impair immune status as a component of disease progression, which is consistent with the previous literature [47]. Analyses that compared markers of oxidative stress with the severity of the disease were controlled for HIV viral load and antiretroviral therapy. 


\section{Cellular Antioxidant Status}

In order to estimate the level of oxidative stress in each participant, the three types of glutathione (GSH) naturally occurring in the body (total, reduced and oxidized forms) were measured using a colorimetric detection kit (Table II). Average concentration of oxidized glutathione (GSSG) was 217.6 uM for the HIV mono-infected group and 270.4 uM for the HIV/HCV co-infected group. Percentage of GSSG was $22.52 \%$ for mono-infected subjects and $26.50 \%$ for those who were co-infected. As both concentration and ratio of oxidized glutathione in the HIV/HCV-co-infected group were higher than those in the mono-infected group, the results suggest that HIV patients who have been co-infected with HCV generate higher oxidative stress and that they may suffer from more oxidative damage than HIV mono-infected individuals. The relationship between $\mathrm{HIV} / \mathrm{HCV}$ co-infection and percentage of oxidized glutathione remained significant after controlling for age and gender $(\beta=2.82, \mathrm{SE}=1.13, \mathrm{p}=0.013)$. Glutathione is a powerful small antioxidant molecule, which is produced mainly in the human liver, and plays pivotal roles in metabolic and cell-cycle-related functions [8]-[12]. GSH levels have been investigated in a varieties of disorders, including alcohol damage [48], respiratory disease [49], cancer [50]-[51], digestive disorders [52], diabetes [53], HIV/AIDS and HCV infections [28], [54]. A decrease in GSH levels with concomitant decrease in oxidized glutathione (GSSG) cause neurotoxicity due to oxidative stress in rats [55]. A recent report demonstrated that $\mathrm{HIV}$ and $\mathrm{HCV}$ may cooperatively drive hepatic fibrogenesis via induction of oxidative stress and inhibition of NFאB activation [56]. Taken together, the results suggest that increased level of GSSG may contribute to fibrogenesis in $\mathrm{HIV} / \mathrm{HCV}$ co-infected subjects. 8-oxo-2' deoxyguanosine (8-oxo-dG) To investigate oxidative damage of mitochondrial DNA (mtDNA), quantitative real-time PCR detecting the level of mtDNA damage caused by mutagenic 8-oxo-dG was performed using $80 \mathrm{ng}$ of total genomic DNA extracted from PBMCs. Threshold cycle $(\mathrm{Ct})$ values were obtained for both enzyme-treated and non-enzyme-treated samples $\left(\mathrm{Ct}_{2}\right.$ and $\mathrm{Ct}_{1}$, respectively). Mean difference of threshold cycle $\left(\mathrm{Ct}_{2}-\mathrm{Ct}_{1}=\Delta \mathrm{Ct}\right)$ was measured at 0.64 for $\mathrm{HIV}$ mono-infected group and 0.43 for $\mathrm{HIV} / \mathrm{HCV}$ co-infected. Thus the mtDNA damage in the HIV/HCV co-infected participants was higher than that in the HIV mono-infected participants. When the threshold cycles were analyzed separately, the enzyme-treated $\mathrm{Ct}_{2}$ values between the mono-infected and co-infected groups showed similar mean values (16.21 for mono-infected and 16.17 for co-infected) while non-enzyme-treated $\mathrm{Ct}_{1}$ mean values were significantly different (15.57 for mono-infected and 15.74 for co-infected, $\mathrm{p}=0.002$ ) (Table III). The higher mean $\mathrm{Ct}_{1}$ value observed in the HIV/HCV co-infected group indicates that these subjects have a lower mtDNA copy number. In summary, the HIV/HCV co-infected subjects had more mtDNA damage and a lower mtDNA copy number than the HIV mono-infected patients.

TABLE II: COMPARISON OF REDUCED AND OXIDIZED GLUTATHIONE LEVELS IN HIV/HCV CO-INFECTION AND HIV MONO-INFECTION.

\begin{tabular}{lllll}
\hline Characteristic & $\begin{array}{l}\text { Overall } \\
(\boldsymbol{n}=\mathbf{1 9 2})\end{array}$ & $\begin{array}{l}\text { HIV/HCV } \\
(\boldsymbol{n}=\mathbf{8 9})\end{array}$ & $\begin{array}{l}\text { HIV only } \\
(\boldsymbol{n}=\mathbf{1 0 3})\end{array}$ & P-value \\
\hline Oxidized form (uM) & 242.06 & 270.40 & 217.60 & 0.0001 \\
Oxidized form (\%) & 24.51 & 26.50 & 22.52 & $0.0005^{*}$ \\
\hline
\end{tabular}

*Indicates statistically significant results

TABLE III: COMPARISON OF MITOCHONDRIAL DNA DAMAGE IN HIV/HCV CO-INFECTION AND HIV MONO-INFECTION.

\begin{tabular}{lccc}
\hline Characteristic & $\begin{array}{c}\text { Overall } \\
(\boldsymbol{n}=\mathbf{1 9 2})\end{array}$ & $\begin{array}{c}\text { HIV/HCV } \\
(\boldsymbol{n}=\mathbf{8 9})\end{array}$ & $\begin{array}{c}\text { P-value } \\
\end{array}$ \\
\hline Average $\mathrm{Ct}_{1}$ (no-enzyme treated) & $15.74 \pm 0.71$ & $15.57 \pm 1.26$ & 0.304 \\
Average $\mathrm{Ct}_{2}$ (enzyme treated) & $16.17 \pm 1.10$ & $16.21 \pm 1.48$ & 0.854 \\
$\Delta \mathrm{Ct}\left(=\mathrm{Ct}_{2}-\mathrm{Ct}_{1}\right)$ & $0.43 \pm 0.51$ & $0.64 \pm 0.04$ & $0.002 *$ \\
\hline
\end{tabular}

*Indicates statistically significant results

\section{Liver Fibrosis}

In a comparison of oxidative stress levels in HIV/HCV co-infected subjects between those with low $(<1.45)$ and high (>1.45) FIB-4 values, no significant results were observed in levels of CD4 cell count, HIV viral load, 8-oxo-dG or percent oxidized glutathione. However, in subjects for whom liver biopsy results were available, a significant positive relationship was observed for both liver fibrosis and activity with the concentration of oxidized glutathione, and of liver fibrosis with HIV viral load (Figures 1 and 2). Although only a small number of the study subjects had biopsy results at this time $(n=11)$, liver biopsy represents the gold standard for assessing liver fibrosis and inflammation [57]. This indicates that even though FIB-4 does not appear to have a correlation with the targeted markers, liver fibrosis appears to be related to increased oxidative stress and HIV replication in HIV/HCV co-infected individuals. 


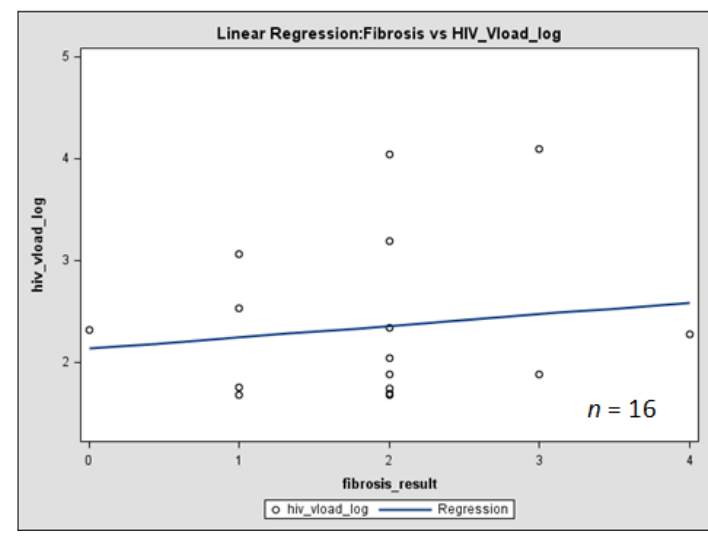

Fig. 1

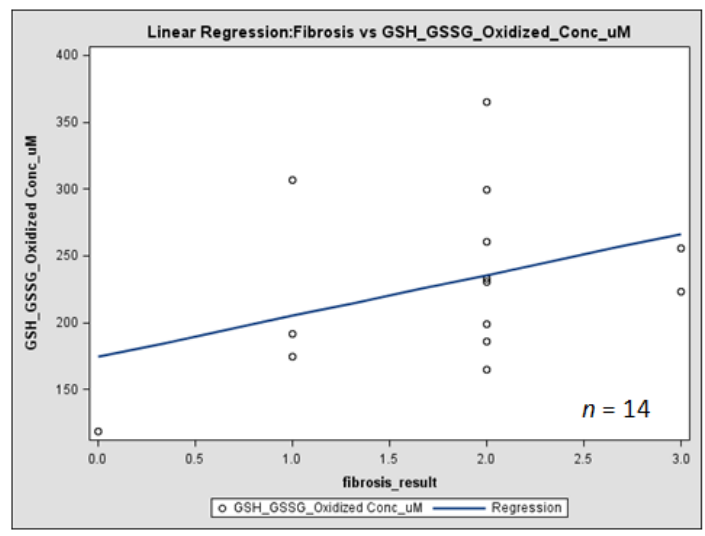

Fig. 2

Fig. 1 and 2. Correlation of liver disease progression with HIV viral load and oxidative stress. Figure 1 indicates correlation between liver fibrosis and HIV viral load; figure 2 represents correlation between liver fibrosis and oxidized GSSG level.

\section{CONCLUSION}

In conclusion, higher oxidized glutathione level and higher mtDNA damage were observed in the HIV/HCV co-infected group, compared to the HIV mono-infected group. In addition, lower mtDNA copy number and more progressive FIB-4 were shown in the HIV/HCV co-infected group. This suggests that $\mathrm{HIV} / \mathrm{HCV}$ co-infection diminishes the capacity of the antioxidant system to control oxidative stress, and may increase HIV replication and decrease mtDNA gene copy number. Longitudinal studies are needed to evaluate cause and effect, and to design interventions to improve the antioxidant capacity by stimulating the enzymatic antioxidant system or supplementing effective antioxidants in HIV/HCV co-infected patients.

\section{ACKNOWLEDGMENT}

We thank the study participants for their participation in this project and the FIU Borinquen Health Study Clinic for their enthusiastic support. This work was supported by the National Institute on Drug Abuse (Grant No. R01DA023405).

\section{REFERENCES}

[1] R. A. Weiss, "How does HIV cause AIDS?," Science, vol. 260, no. 5112, pp. 1273-1279, 1993.

[2] D. C. Douek, M. Roederer, and R. A. Koup, "Emerging Concepts in the Immunopathogenesis of AIDS," Annu. Rev. Med., vol. 60, pp. 471-484, 2009

[3] K. J. Ryan and C.G. Ray, Sherris Medical Microbiology, 4th ed. McGraw Hill. 2004, pp. 551-552.

[4] N. De Maria, A. Colantoni, S. Fagiuoli, G. J. Liu, B. K. Rogers, F. Farinati et al., "Association between reactive oxygen species and disease activity in chronic hepatitis C," Free Radic Biol Med, vol. 21, no. 3, pp. 291-295, 1996

[5] F. Farinati, R. Cardin, N. De Maria, G. D. Liberal, C. Marafin, E. Lecis, et al., "Iron storage, lipid peroxidation and glutathione turnover in chronic anti-HCV positive hepatitis," Journal of Heparoiogy, 1995, vol. 22, pp. 449-456.

[6] K. Moriya, K. Nakagawa, T. Santa, Y. Shintani, H. Fujie, H. Miyoshi et al., "Oxidative stress in the absence of inflammation in a mouse model for hepatitis C virus-associated hepatocarcinogenesis," Cancer Res.2001, vol. 61, pp. 4365-4370.

[7] M. Cohen and L. Patrick. "HCV/HIV Coinfection: Naturopathic treatment options," in Hepatitis C Choices: diverse viewpoints and choices for your hepatitis $C$ journey, $4^{\text {th }}$ ed. Oregon City, Oregon: Caring Ambassadors Program, Inc., 2008, pp. 305-309.
[8] J. Vina, J. R. Vinar, and G. T. Saez, "Glutathione: metabolism and physiological functions," Life Chem. Rep., vol. 4, pp.1-35, 1986.

[9] D. Dolphin, O. Avramovic, and P. Poulson, Glutathione: Coenzymes and Cofactors, Wiley, New York, 1989, vol. 3A and 3B.

[10] N. Taniguchi, T. Higashi, Y. Sakamoto, and A. Meister, Glutathione Centennial., Academic, New York, 1989.

[11] M. Poot, H. Teubert, P.S. Rabinovitch, and T.J. Kavanagh, J. Cell. Physiol., 1995, vol. 163, pp.555-560.

[12] D. C. Adamson, B. Wildemann, M. Sasaki, J. D. Glass, J. C. McArthur, V.I. Christov et al., "Immunologic NO synthase: elevation in severe AIDS dementia and induction by HIV-1 gp41," Science, vol. 274, no. 5294, pp.1917-1919, 1996.

[13] X. Shan, T. Y. Aw, and D. P. Jones, "Glutathione-dependent protection against oxidative injury," Pharmacol.Ther, vol. 47, pp. 61-71, 1990.

[14] S. H. Thomas, "Paracetamol (acetaminophen) poisoning," Pharmacol. Ther, vol. 60, pp. 91-120, 1993.

[15] F. Muller, P. Aukrust, A. M. Svardal, R. K. Eerge, P. M. Ueland, and S. S. Frøland, "The thiols glutathione, cysteine, and homocysteine inhuman immunodeficiency virus (HIV) infection," Nutrients and Foods in AIDS, 1st ed. In: Watson RR, Ed. New York: New York, 1998, pp. 35-69.

[16] N. Cutler. (July, 2007). HCV and the body's most important antioxidant. Barnett Educational Services. [Online]. Available: http//www.hepatitis-central.com/mt/archives/2007/07/hcv_and_the_b od.html

[17] H.-P. Eck, H. Gmunder, M. Hartmann, D. Petzoldt, V. Daniel, and W. Droge. "Low concentrations of acid-soluble thiol (cysteine) in the blood plasma of HIV-1-infected patients," Biol. Chem. Hoppe-Seyler, vol. 370, pp. 101-108,1989.

[18] B. Helbling, J. Von Overbeck, and B. H. Lauterburg. "Decreased release of glutathione into the systemic circulation of patients with HIV infection," Eur.J. Clin. Invest., vol. 26, pp.38-44, 1996.

[19] R. Buhl, K. J. Holroyd, A. Mastrangeli, A. M. Cantin, H. A. Jaffe, F. B. Wells, et al., "Systemic glutathione deficiency in symptom-free HIV-seropositive individuals," Lancet, 1989, vol. 2, no. 8675. pp. 1294-1298.

[20] B. de Quay, R. Malinverni, and B. H. Lauterburg. "Glutathione depletion in HIV-infected patients: role of cysteine deficiency and effect of oral N-acetylcysteine," AIDS, vol. 6, pp.815-819, 1992.

[21] M. Roederer, F. J. T. Staal, H. Osada, L. A. Herzenberg, and L. A. Herzenberg, "CD4 and CD8 T cells with high intracellular glutathione levels are selectively lost as the HIV infection progresses," Int. Immunol., vol. 3, pp. 933-937, 1991.

[22] F. J. T. Staal, M. Roederer, D. M. Israelski, J. Bubp, L. A. Mole, D. McShane, et al., "Intracellular glutathione levels in $\mathrm{T}$ cell subsets decrease in HIV-infected individuals," AIDS Res. HumanRetroviruses, vol. 8, pp.305-314, 1992.

[23] G. M. Adamson and R. E. Billings, "Tumor necrosis factor induced oxidative stress in isolated mouse hepatocytes," Arch. Biochem. Biophys., vol. 294, pp.223-229, 1992.

[24] F. J. T. Staal, M. T. Anderson, G. E. J. Staal, L. A. Herzenberg, C. Gitler, and L. A. Herzenberg, "Redox regulation of signal transduction: tyrosine phosphorylation and calcium influx," Proc. Natl. Acad. Sci.USA, vol. 91, pp.3619-3622, 1994.

[25] F. J. T. Staal, M. Roederer, L. A. Herzenberg, and L. A. Herzenberg, "Intracellular thiols regulate activation of nuclear factor kappa B and 
transcription of human immunodeficiency virus," Proc. Natl. Acad. Sci. USA, 1990, vol. 87, pp.9943-9947.

[26] S. Mihm, J. Ennen, U. Pessara, R. Kurth, and W. Droge. "Inhibition of HIV-1 replication and NF-kappa B activity by cysteine and cysteine derivatives," AIDS 1991, vol. 5, pp. 497-503.

[27] A. Fernandez, J. Kiefer, L. Fosdick, and D.J. McConkey. "Oxygen radical production and thiol depletion are required for $\mathrm{Ca}(2+)$ mediated endogenous endonuclease activation in apoptotic thymocytes," J. Immunol. 1995, vol. 155, pp. 5133-5139.

[28] L. A. Herzenberg, S. C. De Rosa, J. G. Dubs, M. Roederer, M. T. Anderson, S.W. Ela et al. , "Glutathione deficiency is associated with impaired survival in HIV disease," in Proc. Natl. Acad. Sci.USA, 1997, vol. 94, pp.1967-1972.

[29] J. S. James. "Stanford NAC study: glutathione level predicts survival," AIDS Treat News. 1997, vol. 266, pp. 1-5.

[30] S.C. De Rosa, M. D. Zaretsky, J. G. Dubs, M. Roedere, M. Anderson, A. Green et al., "N-acetylcysteine replenishes glutathione in HIV infection," European J Clin Invest. 2000, vol. 30, pp. 915-929.

[31] G. Barbaro, G. Di Lorenzo, M. Soldini, S. Parrotto, G. Bellomo, G. Belloni et al., "Hepatic glutathione deficiency in chronic hepatitis $\mathrm{C}$ : quantitative evaluation in patients who are HIV positive and HIV negative and correlations with plasmatic and lymphocytic concentrations and with the activity of the liver disease," AmJGastroenterol. 1996, vol. 91, pp.2569-2573.

[32] T. Hulgan, J. Morrow, R. T. D’Aquila, S. Raffanti, M. Morgan, P. Rebeiro, and D.W. Haas, "Oxidant stress is increased during treatment of human immunodeficiency virus infection," Clin Infect Dis., vol. 37, no. 12. pp. 1711-1717, 2003.

[33] B. J. Day and W. Lewis, "Oxidative stress in NRTI-induced toxicity: evidence from clinical experience and experiments in vitro and in vivo," Cardiovascular Toxicology, vol. 4, no. 3, pp. 207-216, 2004.

[34] G. N. Kumar, J. Dykstra, E. M. Roberts, V. K. Jayanti, D. Hickman, J.Uchic, et al. "Potent inhibition of the cytochrome P-450 3A-mediated human liver microsomal metabolism of a novel HIV protease inhibitor by ritonavir: a positive drug-drug interaction," Drug MetabDispos., vol. 27, no. 8. pp. 902-908, 1999.

[35] W. Lewis, "Mitochondrial dysfunction and nucleoside reverse transcriptase inhibitor therapy: experimental clarifications and persistent clinical questions," Antiviral Research, vol. 58, no. 3, pp. 189-197, 2003.

[36] A. Cossarizza and G. Moyle, "Antiretroviral nucleoside and nucleotide analogues and mitochondria," AIDS, vol. 18, no. 2. pp. 137-151, 2004

[37] J. de La Asunci, M. L. del Olmo, J. Sastre, A. Millán, A. Pellín, F.V. Pallardó, and J. Viña, "AZT treatment induces molecular and ultrastructural oxidative Journal of Biomedicine and Biotechnology 7 damage to muscle mitochondria. Prevention by antioxidant vitamins." J Clin Invest., vol. 102, no. 1. pp. 4-9, 1998.

[38] C. M. Shikuma, M. Gerschenson, D. Chow, D. E. Libutti, J.H. Willis, J. Murray, et al. "Mitochondrial oxidative phosphorylation protein levels in peripheral blood mononuclear cells correlates with levels in subcutaneous adipose tissue within samples differing by HIV and lipoatrophy status."AIDS Res. Hum. Retroviruses, vol. 24, pp. 1255-1262, 2008.

[39] C. S. Lin, L. S. Wang, C. M. Tsai, and Y. H. Wei, "Low copy number and low oxidative damage of mitochondrial DNA are associated with tumor progression in lung cancer tissues after neoadjuvant chemotheraphy," Interact CardioVascThorac Surg. 2008, vol. 7, pp. 954-958.

[40] P. A. Van Der Kemp, D. Thomas, R. Barbey, R. De Oliveira, S. Boiteux, "Cloning and expression in Escherichia coli of the OGG1 gene of Saccharomyces cerevisiae, which codes for a DNA glycosylase that excises 7, 8-dihydro-8-oxoguanine and 2,
6-diamino-4-hydroxy-5-N-methylformamidopyrimidine," in Proc. NatlAcadSci USA. 1996, vol. 93, pp. 5197-5202.

[41] H. M. Nash, S. D. Bruner, O. D. Scharer, T. Kawate, T. A. Addona, E. Spooner et al., "Cloning of a yeast 8-oxoguanine DNA glycosylase reveals the existence of a base-excision DNA-repair protein superfamily," Curr Biol. 1996, vol. 6, pp. 968-980.

[42] R. K. Bai, C. L. Perng, C. H. Hsu, and L. J. Wong, "Quantitative PCR analysis of mitochondrial DNA content in patients with mitochondrial disease," Ann NY Acad Sci., 1011, pp. 304-309, 2004.

[43] O. W. Griffith and A. Meister, Glutathione: Interorgan translocation, turnover, and metabolism., Proc. Natl. Acad. Sci. USA., vol. 76, pp. 5606-5610, 1979 .

[44] O. W. Griffith, "Determination of glutathione and glutathione disulfide using glutathione reductase and 2 vinylpyridine," Anal.Biochem, vol 106, pp. 207-212, 1980

[45] M. K. Baum, S. Sales, D. T. Jayaweera, S. Lai, G. Bradwin, C. Rafie et al., "Coinfection with hepatitis $\mathrm{C}$ virus, oxidative stress and antioxidant status in HIV-positive drug users in Miami," HIV Med., vol. 12, no. 2, pp. 78-86, 2011.

[46] R. K. Sterling, E. Lissen, N. Clumeck, R. Sola, M.C. Correa, J. Montaner et al., "APRICOT Clinical Investigators. Development of a simple noninvasive index to predict significant fibrosis in patients with HIV/HCV coinfection," Hepatology, vol. 43, no. 6, pp. 1317-1325, 2006

[47] H. K. Monga, M. C. Rodriguez-Barradas, K. Breaux, K. Khattak, C. L. Troisi, M. Velez, et al. "Hepatitis C virus infection-related morbidity and mortality among patients with human immunodeficiency virus infection," Clin Infect Dis., vol. 33, no. 2, pp. 240-247, 2001.

[48] B. H. Lauterburg and M.E. Velez, "Glutathione deficiency in alcoholics: risk factor for paracetamol hepatotoxicity," Gut., vol. 29 , no. 9, pp. 1153-1157, 1988.

[49] I. Rahman and W. MacNee, "Oxidative stress and regulation of glutathione in lung inflammation," Eur. Respir. J., vol. 16, no. 3, pp. 534-554, 2000.

[50] T. Schnelldorfer, S. Gansauge, F. Gansauge, S. Schlosser, H.G. Beger, A.K. Nussler, "Glutathione depletion causes cell growth inhibition and enhanced apoptosis in pancreatic cancer," Cancer, vol. 89, no. 7, pp. 1440-1447, 2000.

[51] T. Coban, A. Mabsout, B.C. Eke, D. Bulbul, U. Berberoglu, and M. Iscan, "Glutathione and lipid peroxidation levels in human breast tumors,"Neoplasma., vol. 45, no. 3, pp. 151-156, 1998.

[52] O. Miralles-Barrachina, G. Savoye, et al. "Low levels of glutathione in endoscopic biopsies of patients with Crohn's colitis: the role of malnutrition," Clin. Nutr., vol. 18, no. 5, pp. 313-317, 1999.

[53] S.I. Rizvi and M.A. Zaid, "Intracellular reduced glutathione content in normal and type 2 diabetic erythrocytes: effect of insulin and (-)epicatechin," J. Physiol. Pharmacol., vol. 52, no. 3, pp. 483-488, 2001.

[54] K. Tanaka, M. Ikeda, A. Nozaki, N. Kato, H. Tsuda, S. Saito, and H. Sekihara, "Lactoferrin inhibits hepatitis C virus viremia in patients with chronic hepatitis C: a pilot study," Jpn. J. Cancer. Res., vol. 90, no. 4, pp. 367-371, 1999.

[55] K. Facecchia, L-A. Fochesato, S.D. Ray, S.J. Stohs, and S. Pandey, "Oxidative toxicity in neurodegerative disease: role of mitochondria dysfunction and therapeutic strategies," J. Toxicol., pp. 1-12, 2011.

[56] W. Lin, G. Wu, S. Li, E.M. Weinberg, K. Kumthip, L.F. Peng, et al "HIV and HCV cooperatively promote hepatic fibrogenesis via induction of reactive oxygen species and NFאB," J. Biol. Chem., vol. 286, no. 4, pp. 2665-2674, 2011

[57] A. Vallet-Pichard, V. Mallet, B. Nalpas, V. Verkarre, A. Nalpas, V. Dhalluin-Venier et al., "FIB-4: an inexpensive and accurate marker of fibrosis in HCV infection. Comparison with liver biopsy and fibrotest," Hepatology, vol. 46, pp. 32-36, 2007. 
International Journal of Bioscience, Biochemistry and Bioinformatics, Vol. 2, No. 3, May 2012 